\title{
Níveis de fibra em detergente neutro forrageiro na alimentação de ovelhas Santa Inês gestantes
}

\author{
[Level of fiber on feeding of Santa Ines pregnant ewes]
}

\author{
G.L. Macedo Junior ${ }^{1}$, P.M. França ${ }^{2}$, R.M. Assis ${ }^{2}$, T.R.V. Almeida' ${ }^{2}$, O.J. Paula ${ }^{2}$, J.R.O. Pérez ${ }^{3}$, \\ A.A.F. Baião ${ }^{2}$, I. Borges ${ }^{4}$, V.B. Silva ${ }^{1}$ \\ ${ }^{1}$ Aluno de pós-graduação - EV-UFMG - Belo Horizonte, MG \\ ${ }^{2}$ Aluno de pós-graduação - UFLA - Lavras, MG \\ ${ }^{3}$ Departamento de Zootecnia - UFLA - Lavras, MG \\ ${ }^{4}$ Escola de Veterinária - UFMG - Belo Horizonte, MG
}

\begin{abstract}
RESUMO
Avaliaram-se o consumo, a digestibilidade aparente e o comportamento ingestivo de ovelhas no terço final de gestação com dietas contendo diferentes níveis de fibra em detergente neutro forrageiro (FDNf). Foram utilizadas 16 ovelhas adultas da raça Santa Inês, distribuídas em um delineamento inteiramente ao acaso, com quatro tratamentos: 9, 17, 26 e 35\% de FDNf. Os consumos de matéria seca, matéria orgânica, proteína bruta, energia bruta, energia digestível e energia metabolizável não foram influenciados pelos tratamentos, e os consumos de fibra em detergente neutro (FDN) e de fibra em detergente ácido (FDA) aumentaram com maiores níveis de FDNf. As digestibilidades do FDN e FDA e o tempo gasto pelos animais com ruminação também aumentaram com maiores níveis de FDNf na dieta. Dietas com maior quantidade de FDNf influenciaram comportamento ingestivo e digestibilidade de ovelhas em fase final de lactação.
\end{abstract}

Palavras-chave: ovelha, fibra, metabolismo, ruminação

\begin{abstract}
The intake, apparent digestibility and feeding behavior of pregnant ewes ped diets containing different levels of neutral detergent fiber (NDF) were evaluated. Sixteen Santa Inês ewes were randomly assigned to four treatments with 9, 17, 26 e 35\% of NDF. Dry matter (DM), organic matter, crude protein, crude energy, digestible energy and metabolizable energy intake were not affected by the level of NDF in the diet, however, $N D F$ and acid detergent fiber (ADF) intake increased with the increase of NDF diet levels. The apparent digestibility of the NDF and ADF and rumination time increased with the NDF diet level. Higher NDF diet levels influenced feeding behavior and apparent digestibility of ewes at the end of the lactation period.
\end{abstract}

Keywords: ewe, fiber, metabolism, rumination

\section{INTRODUÇ̃̃O}

Fibra é um termo meramente nutricional, e sua definição está vinculada ao método analítico empregado na sua determinação. Quimicamente, a fibra é um agregado de compostos e não uma entidade química distinta, portanto a composição química da fibra é dependente da sua fonte e da metodologia usada na determinação laboratorial (Mertens, 1992). Embora o papel da fibra na disponibilidade de energia e fermentação ruminal seja frequentemente reconhecido, o seu papel na regulação do consumo não tem sido muito bem aceito. Muito da controvérsia é devido à falta de reconhecimento da complexidade e das interações de compensações que ocorrem ao se

Recebido em 5 de junho de 2008

Aceito em 13 de janeiro de 2009

E-mail: gilbertomacedojr@gmail.com

Apoio: $\mathrm{CNPq}$ 
determinar o consumo de um determinado grupo de animais alimentados com uma dieta específica.

A digestibilidade da fibra é definida como a proporção da fỉbra ingerida que não é excretada nas fezes. A fibra tem uma fração não digestível e outra potencialmente digestível. O processo da digestão da fibra consiste na hidrólise dos polissacarídeos e a conversão dos monossacarídeos resultantes em ácidos graxos voláteis (AGV), gases da fermentação e calor (Tamminga et al., 1990). A taxa de hidrólise geralmente é o fator limitante na digestão ruminal da fibra (Van Soest, 1994). A digestibilidade da fibra e das forragens não é constante para todos os animais ou para todas as condições de alimentação, mas a principal fonte de variação decorre das diferenças na sua estrutura, composição química e estágio de maturidade.

A capacidade de o animal consumir alimentos em quantidades suficientes, para alcançar suas exigências de mantença e produção, é um dos fatores mais importantes em sistemas de produção, principalmente se esses forem em grande parte dependentes de volumosos (Sniffen et al., 1993). O consumo é regulado por vários fatores, tais como: alimento (fibra, densidade energética e volume), animal (peso, nível de produção e estado fisiológico) e condição de alimentação (disponibilidade de alimento, freqüência de alimentação, dentre outros), como descrito por Mertens (1992).

O comportamento alimentar tem sido estudado com relação às características dos alimentos, à motilidade do pré-estômago, ao estudo e ao ambiente. A diversidade de objetivos e as condições experimentais conduziram a várias opções de técnicas de registro de dados, na forma de observações visuais, registro semiautomático e automático e parâmetros selecionados para descrição do comportamento ingestivo, como tempo de alimentação ou ruminação, número de alimentações, períodos de ruminação e eficiência de alimentação e ruminação (Dulphy et al., 1980; Forbes, 1985, citado por Burger et al., 2000). Van Soest (1994) citou que o tempo de ruminação é consideravelmente influenciado pela natureza da dieta e que este aumenta de acordo com o conteúdo do seu FDN.

O objetivo deste trabalho foi avaliar o consumo, a digestibilidade aparente e o comportamento alimentar de ovelhas no terço final de gestação, alimentadas com diferentes níveis de fibra em detergente neutro forrageiro (FDNf) na dieta.

\section{MATERIAL E MÉTODOS}

Foram utilizadas 16 ovelhas no terço final de gestação, com peso médio de $54,1 \pm 5,9 \mathrm{~kg}$, alojadas em gaiolas metabólicas individuais providas de comedouro, bebedouro e cocho para a suplementação mineral.

Os animais foram distribuídos em um delineamento inteiramente ao acaso, com quatro tratamentos que consistiram em diferentes níveis de FDNf na dieta: 9, 17, 26 e 35\% de FDNf.

As dietas oferecidas foram formuladas de acordo com as exigências do (Nutrient..., 1985) e de maneira a serem isoprotéicas. Os alimentos utilizados foram feno de capim coast-cross, milho, farelo de soja e premix mineral (Tab. 1).

Tabela 1. Proporção dos alimentos oferecidos a ovelhas, em função dos diferentes níveis de fibra em detergente neutro forrageiro (FDNf) na dieta

\begin{tabular}{lcccc}
\hline \multirow{2}{*}{ Alimento } & \multicolumn{4}{c}{ FDNf(\%) } \\
\cline { 2 - 5 } & 9 & 17 & 26 & 35 \\
\hline Feno de coast-cross & 10,0 & 20,0 & 30,0 & 40,0 \\
Milho & 66,5 & 56,5 & 46,5 & 37,5 \\
Farelo de soja & 22,5 & 22,5 & 22,5 & 22,5 \\
Premix $^{1}$ & 1,0 & 1,0 & 1,0 & 1,0 \\
\hline
\end{tabular}

${ }^{1}$ Composição= cálcio: $230 \mathrm{~g}$; fósforo: $90 \mathrm{~g}$; enxofre: $15 \mathrm{~g}$; magnésio: $20 \mathrm{~g}$; sódio: $48 \mathrm{~g}$; cobalto: $100 \mathrm{mg}$; cobre: $700 \mathrm{mg}$; ferro: 2.000mg; iodo: $80 \mathrm{mg}$; manganês: $1250 \mathrm{mg}$; selênio: 200mg; zinco: 2.700mg; flúor: $900 \mathrm{mg}$; vit.A: 200.000UI; vit.D3: 60.000UI; vit.E: 60UI. 
Na Tab. 2, encontra-se a composição químicobromatológica das dietas. Estas foram oferecidas duas vezes ao dia ( 8 e $15 \mathrm{~h})$ e distribuídas de maneira que a primeira refeição disponibilizasse $60 \%$ do ofertado diário e permitisse $10 \%$ de sobra.
Cada período experimental teve duração de 15 dias, 10 dias de adaptação à dieta e cinco dias de coleta de amostras. Foram feitas coletas diárias de alimentos e sobras que foram pesadas, acondicionadas em sacos plásticos e armazenadas a $-20^{\circ} \mathrm{C}$ para posteriores análises.

Tabela 2. Composição ${ }^{1}$ químico-bromatológica das dietas oferecidas a ovelhas, em função dos diferentes níveis de fibra em detergente neutro forrageiro (FDNf)

\begin{tabular}{lcccc}
\hline \multirow{2}{*}{ Ingrediente } & \multicolumn{4}{c}{ Nivel de FDNf $(\%)$} \\
\cline { 2 - 5 } & 9 & 17 & 26 & 35 \\
\hline MS & 83,4 & 83,1 & 82,5 & 83,2 \\
FDNf(\%) & 8,7 & 17,3 & 26,0 & 34,7 \\
FDA(\%) & 10,9 & 15,9 & 32,3 & 38,9 \\
PB(\%) & 19,6 & 20,5 & 20,6 & 21,0 \\
Cinzas(\%) & 4,4 & 4,5 & 4,6 & 4,7 \\
MO(\%) & 95,6 & 95,5 & 95,4 & 95,3 \\
EM( kcal/g) & 2.954 & 2.948 & 2.945 & 2.813 \\
\hline
\end{tabular}

${ }^{\mathrm{T}}$ Com base na matéria seca. MS: matéria seca; FDNf: fibra em detergente neutro forrageiro; FDA: fibra em detergente ácido; PB: proteína bruta; MO: matéria orgânica; EM: energia metabolizável.

A coleta total de fezes foi realizada com bandejas plásticas, que foram pesadas, e delas retirada, diariamente, uma amostragem representando o total coletado, que foi acondicionado em sacos plásticos identificados e armazenados a $-20^{\circ} \mathrm{C}$. A urina foi coletada em baldes plásticos com tela separadora, com intuito de evitar que ela se misturasse às fezes. Para evitar perdas de nitrogênio nos baldes, à urina foram adicionados $100 \mathrm{ml}$ de ácido sulfúrico $\left(\mathrm{H}_{2} \mathrm{SO}_{4}\right)$ a $2 \mathrm{~N}$. Esta foi pesada, diariamente, e $10 \%$ de sua alíquota foi separada para armazenagem em freezer a $-20^{\circ} \mathrm{C}$.

Nas amostras de alimentos, nas sobras e nas fezes, foram feitas análises de matéria seca (MS), fibra em detergente neutro (FDN), fibra em detergente ácido (FDA), proteína bruta (PB), energia bruta (EB) e cinzas; na urina foram feitas análises de PB e EB segundo Silva e Queiroz (2002).

A energia metabolizável (EM) foi determinada pela equação: $\mathrm{EM}=\mathrm{EBI}$ - $(\mathrm{EBF}+\mathrm{EBU}+\mathrm{EPGD})$, em que: $\mathrm{EBI}=$ energia bruta ingerida, $\mathrm{EBF}=$ energia bruta das fezes, EBU= energia bruta da urina e $\mathrm{EPGD}=$ energia de perdas e ganho diário, calculada conforme Sniffen et al. (1992).

O comportamento ingestivo foi determinado por um período de 24 horas, em que as avaliações foram feitas de cinco em cinco minutos. Os parâmetros utilizados foram tempos de alimentação, ruminação e ociosidade e tempo gasto em beber água.

Os resultados foram submetidos à análise de variância, ao teste de média e regressão, e a significância dos tratamentos foi avaliada por meio do teste Tukey $(\mathrm{P}<0,05)$.

\section{RESULTADOS E DISCUSSÃO}

Na Tab. 3, são apresentados os consumos médios diários de MS, matéria orgânica (MO), EB, energia digestível (ED), EM PB, PD, FDN e FDA, os coeficientes de determinação $\left(r^{2}\right)$ e as equações de regressão em função dos diferentes níveis de FDN forrageiro na dieta.

Não houve diferença no consumo de MS entre os tratamentos. Isto pode ser atribuído ao fato de as ovelhas estarem no último terço de gestação, pois nessa fase o volume do útero pressiona o rúmen, o que diminuiria a sua capacidade de ingestão. As dietas em fase final de gestação são naturalmente mais densas, em razão da alta exigência dos animais, o que pode influir no consumo. Segundo Silveira (2002), a depressão no consumo pode estar associada à grande quantidade de carboidratos solúveis na dieta; já Van Soest (1982) cita que a sensação de saciedade está relacionada à densidade calórica da dieta. 
Níveis de fibra em detergente...

Tabela 3. Consumo de nutrientes segundo o nível de fibra em detergente neutro forrageiro (FDNf) e equações de regressão ajustados, obtidos com ovelhas em gestação

\begin{tabular}{|c|c|c|c|c|c|}
\hline \multirow{2}{*}{ Variável } & \multicolumn{4}{|c|}{ FDNf $(\%)$} & \multirow{2}{*}{$\mathrm{CV}(\%)$} \\
\hline & 9 & 17 & 26 & 35 & \\
\hline CMS (g/kg $\left.{ }^{0,75}\right)$ & 78,30 & 66,33 & 80,47 & 78,79 & 21,84 \\
\hline $\mathrm{CMO}\left(\mathrm{g} / \mathrm{kg}^{0,75}\right)$ & 75,14 & 63,51 & 76,93 & 74,85 & 21,10 \\
\hline $\mathrm{CEB}\left(\mathrm{kcal} / \mathrm{kg}^{0,75}\right)$ & 342,9 & 288,0 & 350,6 & 345,8 & 21,00 \\
\hline $\mathrm{CED}\left(\mathrm{kcal} / \mathrm{kg}^{0,75}\right)$ & 240,2 & 203,6 & 244,6 & 238,8 & 22,3 \\
\hline $\mathrm{CEM}\left(\mathrm{kcal} / \mathrm{kg}^{0,75}\right)$ & 216,0 & 178,4 & 220,9 & 211,8 & 23,47 \\
\hline $\mathrm{CPB}\left(\mathrm{g} / \mathrm{kg}^{0,75}\right)$ & 15,23 & 13,42 & 16,03 & 17,37 & 20,12 \\
\hline $\mathrm{CPD}\left(\mathrm{g} / \mathrm{kg}^{0,75}\right)$ & 10,57 & 9,29 & 8,54 & 9,46 & 27,94 \\
\hline $\operatorname{CFDN}\left(\mathrm{g} / \mathrm{kg}^{0,75}\right)$ & 22,43 & 23,53 & 32,64 & 34,37 & 19,81 \\
\hline \multirow[t]{2}{*}{ CFDA $\left(\mathrm{g} / \mathrm{kg}^{0,75}\right)$} & 8,77 & 10,40 & 13,42 & 17,63 & 19,86 \\
\hline & \multicolumn{4}{|c|}{ Equação de regressão } & $r^{2}(\%)^{*}$ \\
\hline$\overline{\mathrm{CFDN}}$ & \multirow{2}{*}{\multicolumn{4}{|c|}{$\begin{array}{c}\hat{Y}=16,926695+0,520046 X \\
\hat{Y}=5,153841+0,341479 X\end{array}$}} & 48,84 \\
\hline CFDA & & & & & 68,33 \\
\hline
\end{tabular}

CMS: consumo de matéria seca; CMO: consumo de matéria orgânica; CEB: consumo de energia bruta; CED: consumo de energia digestível; CEM: consumo de energia metabolizável; CPB: consumo de proteína bruta; CPD: consumo de proteína digestível; CFDN: consumo de fibra em detergente neutro; CFDA: consumo de fibra em detergente ácido.

*Significativo ao nível de 5\% da probabilidade.

Os consumos de MO, EB, ED, EM, PB e PD não diferiram entre os tratamentos, e isso, provavelmente, ocorreu em razão de o consumo de MS também não ter variado. Além disso, as dietas eram isoproteicas, o que não permitiu maior variação no consumo de PB e PD.

O NRC (Nutrient..., 1985) preconiza que, para ovelhas em final de gestação, o consumo de EM esperado seja de $3.600 \mathrm{kcal} / \mathrm{d}$. Neste trabalho, as ovelhas consumiram mais, em média $4.463 \mathrm{kcal} / \mathrm{d}$.

CFDN e CFDA apresentaram aumento linear com o aumento dos níveis de FDNf na dieta. O consumo de FDN foi de $34,4 \mathrm{~g} / \mathrm{PV}^{0,75}$ na dieta com $35 \%$ FDNf e de $22,4 \mathrm{~g} / \mathrm{PV}^{0,75}$ na dieta com $9 \%$ FDNf. Silva Sobrinho et al. (2002), ao trabalharem com diferentes níveis de concentrado na dieta de ovelhas lanadas e deslanadas, observaram que, nos animais que consumiram a dieta com $60 \%$ de concentrado, o consumo de FDN foi similar, com valores de $35,5 \mathrm{~g} / \mathrm{PV}^{0,75}$.

O fato de os consumos de MS e de EM terem sido estáveis e acima do preconizado pelo NRC e o de FDN ter aumentado nas dietas com maior teor de FDNf sugere que dietas com mais fibra (35\% FDNf) permitiram um consumo energético que satisfizesse as exigências nutricionais desses animais.

$\mathrm{Na}$ Tab. 4, são apresentados os coeficientes de digestibilidade aparente da MS, MO, EB, PB, FDN e FDA, os coeficientes de variação e de determinação, e as equações de regressão em função dos níveis de FDN forrageiro na dieta.

Tabela 4. Digestibilidade aparente de nutrientes segundo o nível de fibra em detergente neutro forrageiro (FDNf) e equações de regressão ajustadas, obtidas com ovelhas em gestação

\begin{tabular}{|c|c|c|c|c|c|}
\hline \multirow{2}{*}{ Variável } & \multicolumn{4}{|c|}{ FDNf $(\%)$} & \multirow[t]{2}{*}{$\mathrm{CV}(\%)$} \\
\hline & 9 & 17 & 26 & 35 & \\
\hline DMS(\%) & 71,0 & 72,6 & 69,9 & 68,8 & 6,29 \\
\hline $\mathrm{DMO}(\%)$ & 72,8 & 74,5 & 71,6 & 70,0 & 5,85 \\
\hline $\operatorname{DEB}(\%)$ & 70,0 & 71,5 & 69,6 & 69,1 & 6,5 \\
\hline $\mathrm{DPB}(\%)$ & 69,2 & 68,5 & 52,7 & 54,5 & 11,8 \\
\hline DFDN(\%) & 51,2 & 56,2 & 55,7 & 56,2 & 13,74 \\
\hline \multirow[t]{2}{*}{ DFDA( $(\%)$} & 46,2 & 60,2 & 43,7 & 55,2 & 13,35 \\
\hline & \multicolumn{4}{|c|}{ Equação de regressão } & $\mathrm{r}^{2}(\%)^{*}$ \\
\hline DPB & \multicolumn{4}{|c|}{$\hat{\mathrm{Y}}=0,762452-0,006917 \mathrm{X}$} & 41,8 \\
\hline
\end{tabular}

DMS: digestibilidade da matéria seca; DMO: digestibilidade da matéria orgânica; DEB: digestibilidade da energia bruta; DPB: digestibilidade da proteína bruta; DFDN: digestibilidade da fibra em detergente neutro; DFDA: digestibilidade da fibra em detergente ácido.

*Significativo ao nível de $5 \%$ de probabilidade. 
O coeficiente de digestibilidade da MS não variou com o aumento dos níveis de FDNf na dieta, apresentando valores médios de $70 \%$. Esse comportamento também foi verificado na $\mathrm{MO}$ e na EB. Macedo Junior (2004), ao trabalhar com tratamentos semelhantes, em ovelhas não gestantes, observou comportamento diferente, em que, à medida que se aumentou o nível de FDNf, houve aumento da digestibilidade da MS e da MO. O avançado estádio de gestação pode ter influenciado estes resultados.

O coeficiente de digestibilidade da PB teve comportamento linear, diminuindo à medida que se aumentou a quantidade de FDNf na dieta. Esse comportamento pode ser atribuído à diminuição da quantidade de concentrado na dieta. Segundo Valadares Filho (1985), carboidratos não estruturais apresentam coeficiente de digestibilidade acima de $90 \%$ e os carboidratos estruturais, digestibilidade próxima de 50\%. Silva Sobrinho. (2002) encontraram resultados semelhantes quando trabalharam com diferentes níveis de concentrado na dieta de ovelhas lanadas e deslanadas, no entanto Macedo Junior (2004), ao trabalhar com ovelhas não gestantes, observou comportamento diferente, em que, à medida que se aumentou a quantidade de FDNf na dieta, maior foi a digestibilidade da PB. Esse autor sugeriu que tal resultado sofreu influência da condição ruminal, isto é, à medida que se elevou o nível de FDNf, melhorou a condição do ambiente ruminal, aumentando, assim, a digestibilidade dos nutrientes.
Esperava-se que o coeficiente de digestibilidade da EB apresentasse comportamento similar ao observado pela $\mathrm{PB}$, no entanto, isso não ocorreu.

A digestibilidade do FDN não apresentou diferença com o aumento de FDNf na dieta, semelhante aos resultados encontrados por Macedo Junior (2004) e Bolzan et al. (2002). O excesso de carboidratos não estruturais (CNE) interfere negativamente na digestão da fibra, e isso pode ocorrer em razão da diminuição do $\mathrm{pH}$ ruminal que desequilibra a flora, sobrepondo as bactérias amilolíticas sobre as fibrolíticas. Outro fator que pode influenciar a digestibilidade do FDN é o fato de os CNE ou o produto de sua digestão inibir a liberação de enzimas que degradam a fibra (Tamminga et al., 1990; Hoover, 1986).

A equação de regressão da digestibilidade do FDA em relação ao teor de FDNf não foram significativas $(\mathrm{P}<0.05)$.

$\mathrm{Na}$ Tab. 5, são apresentados os tempos gastos, em minutos, com alimentação, ociosidade e ruminação, os coeficientes de variação e de determinação, e as equações de regressão em função dos níveis de FDN forrageiro da dieta. $\mathrm{O}$ tempo gasto pelos animais com alimentação (TA) não diferiu entre tratamentos e o tempo gasto com ociosidade (TO) foi influenciado da forma quadrática pelo nível de FDNf da dieta.

Tabela 5. Tempo gasto com ruminação (TR), com alimentação (TA) e de ociosidade (TO) segundo o nível de fibra em detergente neutro forrageiro (FDNf) e equações de regressão ajustadas, obtidas de ovelhas em gestação

\begin{tabular}{|c|c|c|c|c|c|}
\hline \multirow{2}{*}{ Variável } & \multicolumn{4}{|c|}{ FDNf $(\%)$} & \multirow{2}{*}{$\mathrm{CV}(\%)$} \\
\hline & 9 & 17 & 26 & 35 & \\
\hline TR (min) & 241,2 & 341,2 & 447,5 & 337,5 & 18,3 \\
\hline TA (min) & 217,5 & 277,5 & 226,5 & 192,5 & 13,8 \\
\hline TO (min) & 981,2 & 821,2 & 799,2 & 910,0 & 13,8 \\
\hline TA $(\min / \mathrm{kg} \mathrm{MS})$ & 132,5 & 266,4 & 138,8 & 109,7 & 15,7 \\
\hline TA (min/kg FDN) & 251,6 & 342,7 & 461,0 & 729,1 & 16,5 \\
\hline TR (min/kg MS) & 146,5 & 268,5 & 274,3 & 189,8 & 14,3 \\
\hline \multirow[t]{2}{*}{ TR (min/kg FDN) } & 511,1 & 750,8 & 674,0 & 435,9 & 13,2 \\
\hline & \multicolumn{4}{|c|}{ Equação de regressão } & $\mathrm{r}^{2}(\%)^{*}$ \\
\hline TR & \multicolumn{4}{|c|}{$\hat{\mathrm{Y}}=-19,375+302 \mathrm{X}-52,5 \mathrm{X}^{2}$} & $68,6^{*}$ \\
\hline TO & \multicolumn{4}{|c|}{$\hat{Y}=1316,56-406,56 X-75,94 X^{2}$} & $77,9 *$ \\
\hline TR (min/kg MS) & \multicolumn{4}{|c|}{$\hat{Y}=-72,18+31,32 X-0,685 X^{2}$} & $68,4^{*}$ \\
\hline $\mathrm{TR}(\mathrm{min} / \mathrm{kg} \mathrm{FDN})$ & \multicolumn{4}{|c|}{$\hat{Y}=73,33+65,21 X-1,58 X^{2}$} & $64,5^{*}$ \\
\hline
\end{tabular}

*Significativo a $5 \%$ de probabilidade. 
O tempo com ruminação (TR) foi influenciado de forma quadrática pelo nível de FDNf. Esta equação indica que houve aumento no TR até o nível de $26 \%$ de FDNf na dieta. Segundo Dado e Allen (1995), o número de períodos de ruminação aumenta de acordo com o aumento da quantidade de fibra na dieta, refletidas na necessidade de melhor processamento da digesta ruminal, que procura maximizar a eficiência digestiva. Carvalho et al. (2006), ao estudarem o comportamento ingestivo de cabras da raça Alpina alimentadas com diferentes níveis de FDNf, encontraram valores similares aos observados neste trabalho; para níveis de 20, 27 e $34 \%$ de FDNf, os animais despenderam 311, 360 e 393 minutos, respectivamente.

O tempo médio de ruminação estimado no presente trabalho foi de sete horas e meia. Segundo Teixeira e Teixeira (2001), ovinos gastam de oito a nove horas por dia ruminando. O menor tempo com ruminação, obtido neste trabalho, pode ser atribuído ao fato de a dieta estar mais densa e os animais estarem em fase final de gestação.

A relação minutos gastos com ruminação por $\mathrm{kg}$ de MS ou de FDN foi influenciada de forma quadrática pelo nível de FDNf na dieta e até os níveis de 22,86 e 20,64 de FDNf em dieta, o que corresponde ao aumento no consumo de FDN e nas horas gastas com ruminação. Macedo Junior (2004), ao trabalhar com dietas semelhantes com ovelhas não gestantes, não verificou diferenças entre os tratamentos quando se avaliaram minutos de ruminação/kg de MS e FDN consumido.

\section{CONCLUSÕES}

A gestação pode causar alterações no metabolismo do animal modificando o comportamento ingestivo, o consumo e a digestibilidade aparente das dietas. Dietas para ovelhas em fase de final de gestação podem ter em sua composição níveis de FDNf de até 35\% sem comprometer o aporte energético, sendo que o mínimo deve ser de $20 \%$ de FDNf.

\section{REFERÊNCIAS BIBLIOGRÁFICAS}

BOLZAN, I.T.; WEBER, A.; VARGAS Jr., F.M. et al. Comportamento e digestibilidade aparente em ovinos alimentados com diferentes processamentos do grão de milho e três níveis de concentrado. In: REUNIÃO ANUAL DA SOCIEDADE BRASILEIRA DE ZOOTECNIA, 39., 2002, Recife. Anais... Recife: SBZ, 2002. CD-ROM.

BÜRGER, P.J.; PEREIRA, J.C.; QUEIROZ, A.C. Comportamento ingestivo em bezerros holandeses alimentados com dietas contendo diferentes níveis de concentrado. Rev. Bras. Zootec., v.29, p.236-242, 2000.

CARVALHO, S.; RODRIGUES, M.T.; BRANCO, R.H. et al. Comportamento ingestivo de cabras alpinas em lactação alimentadas com dietas contendo diferentes níveis de fibra em detergente neutro proveniente de forragem. Rev. Bras. Zootec., v.35, p.562-568, 2006.

DADO, R.G.; ALLEN, M.S. Intake limitation, feeding behavior and rúmen function of cows challenged with rumen fill from dietary fiber or inert bulk. J. Dairy Sci., v.78, p.118-133, 1995.

DULPHY, J.P.; REMOND, B.; THERIEZ, M. Ingestive behavior and related activities in ruminants. In: RUCKEBUSH, Y.; THIVEND, P. Digestive phisiology and metabolism in ruminants. Lancaster: MTP, 1980. p.103-122.

FORBES, J.M. Voluntary food intake and diet selection in farm animals. Wallingford: CAB, 1995. 532p.

HOOVER, W.H. Chemical factors involved in ruminal fiber digestion. J. Dairy Sci., v.69, p.2755, 1986.

MACEDO JUNIOR, G.L. Influência dos diferentes níveis de FDN dietético no consumo, digestibilidade aparente e comportamento ingestivo de ovelhas Santa Inês. 2004. 127f. Dissertação (Mestrado) - Universidade Federal de Lavras, Lavras, MG.

MERTENS, D.R. Análise da fibra e sua utilização na avaliação de alimentos e formulação de rações. In: SIMPÓSIO INTERNACIONAL DE RUMINANTES, 1992, Lavras. Anais... Lavras: SBZ-ESAL, 1992. p.188

NUTRIENT requirements of sheep. 6.ed. Washington: National Academic, 1985. 99p.

SILVA, J.D.; QUEIROZ, A.C. Análises de alimentos: métodos químicos e biológicos. 2.ed. Viçosa: UFV, 2002. 156p. 
SILVA SOBRINHO, A.G. Efeitos da relação Volumoso:Concentrado e do peso ao abate sobre os componentes da perna de cordeiros Ile de France x Ideal confinados. Rev. Bras. Zootec., v.31, p.1017-1023, 2002.

SILVEIRA, A.L.F. Avaliação nutricional da adição de uréia a dieta baseada em feno de média qualidade suplementada com milho moído. 2002. 124f. Dissertação (Mestrado) Universidade Federal do Rio Grande do Sul, Porto Alegre.

SNIFFEN C.J.; BEVERLY, R.W.; MOONEY, C.S. Nutrient requirements versus supply in the dairy cow: strategies to account for variability. $J$. Dairy Sci., v.73, p.3160-3178, 1993.

SNIFFEN C.J.; O'CONNOR, J.D.; VAN SOEST, P.J. et al. A net carbohydrate and protein system for evaluating cattle diets: II. Carbohydrate and protein availability. J. Anim. Sci., v.70, p.3562-3577, 1992.
TAMMINGA, C.A.; DALE, J.M.; GOODMAN, L. et al. Neuroleptic-induced vacuous chewing movements as an animal model of tardive dyskinesia: A study in three rat strains. Psychopharmacology, v.102, p.474-478, 1990.

TEIXEIRA， J.C.; TEIXEIRA， L.F.A.C. Princípios de nutrição de bovinos leiteiros. Lavras: UFLA/FAEPE, 2001

VALADARES FILHO, S.C. Digestão total e parcial da matéria seca e carboidratos em bovinos e bubalinos. 1985. 148f. Tese (Doutorado) - Universidade Federal de Viçosa, Viçosa.

VAN SOEST, P.J. Nutritional ecology of the ruminant. 1.ed. Corvallis, Oregon: O \& Books, 1982. 373p.

VAN SOEST, P.J. Nutritional ecology of the ruminant. 2.ed. Ithaca: Comstock, 1994. 476p. 